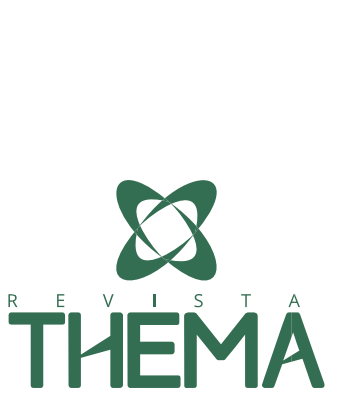

\title{
O Ensino Através de Projetos como Metodologia Ativa de Ensino e de Aprendizagem
}

\author{
Teaching Through Projects as an Active Methodology for \\ Teaching and Learning
}

Cristiano da Silva Buss ${ }^{1}$; Luiz Fernando Mackedanz ${ }^{2}$

\begin{abstract}
RESUMO
O presente artigo tem a intenção de levantar elementos importantes a respeito da metodologia didática envolvendo o ensino através de projetos. O texto irá ilustrar que o uso da aula expositiva tradicional é hegemônico em nossos estabelecimentos de ensino e tem sido alvo de duras críticas pelos defensores de técnicas pedagógicas ditas inovadoras. Mostraremos que tal método deve ser repensado toda vez que sua utilização acarretar em um distanciamento do diálogo educativo entre professor e alunos. Para contornar essa situação, o ensino através de projetos surge como uma via didática que pode reestabelecer o ambiente escolar, aproximando docentes e discentes da responsabilidade de ensinar e aprender. Tal metodologia coloca o professor como coordenador das ações didáticas, oportunizando situações onde o aprendiz torna-se o responsável pela sua própria aprendizagem.
\end{abstract}

Palavras-chave: inovação pedagógica, aula expositiva, projetos de aprendizagem, ensino através de projetos.

\begin{abstract}
This article intends to raise important elements about the didactic methodology involving teaching through projects. The text will illustrate that use of traditional lecture is hegemonic in our educational institutions and has been target of harsh criticism by the proponents of so-called innovative pedagogical techniques. We will show that this method should be reconsidered every time its use entails a distancing of educational dialogue between teacher and students. In order to overcome this situation, teaching through projects appear as a didactic way that can reestablish the school environment, bringing teachers and students to the responsibility of teaching and learning. Such methodology puts the teacher as coordinator of educational actions, creating opportunities for situations where the learner becomes responsible for its own learning.
\end{abstract}

Keywords: pedagogical innovation, lecture, learning projects, teaching through projects.

\footnotetext{
${ }^{1}$ IFSul - Instituto Federal de Educação, Ciência e Tecnologia Sul-rio-grandense, Pelotas/RS - Brasil.

2 FURG - Universidade Federal do Rio Grande - Rio Grande/RS - Brasil.
} 


\section{INTRODUÇÃO}

Muitas coisas têm sido ditas sobre a situação atual da escola e quase todas elas concordam com a iminente crise desta instituição. Não é difícil perceber que os professores estão exaustos e sem ânimo. É possível intuir em suas falas uma aguda carga de pessimismo e elevado estresse que terminam por afetar significativamente sua saúde, sua personalidade e sua prática. Ao mesmo tempo, os alunos não aprendem. É cada vez mais raro encontrar turmas motivadas e interessadas nos conteúdos da grade curricular. Não é que eles não gostem de ir à escola. O problema está na sala de aula e, mais precisamente, na aula em si. O modo como o ensino tem sido conduzido é que, na maioria das vezes, frustra e desmotiva os aprendizes. Enquanto isso, a sociedade em geral também fica desgostosa, pois percebe que o egresso da educação básica não está preparado para o mercado de trabalho, para a continuidade dos estudos e para atividades criativas e empreendedoras. Visto de fora, aparentemente a escola não tem cumprido o seu papel. O resultado é um clima de dúvida pairando sobre os nossos educandários.

Possivelmente não exista uma causa isolada para tudo isso, ou seja, muitos devem ser os fatores que levaram a escola a esse patamar, tais como desvalorização do professor, falta de investimentos na educação, metodologias defasadas, etc. Neste escrito, defendemos que a maneira pela qual as aulas têm sido conduzidas pode ser um dos fatores de desgaste da imagem da escola. Para tentar auxiliar no entendimento dessa situação, este artigo analisa o modo como a maioria das escolas propõem suas práticas didáticas e indica uma alternativa a esta situação. Num primeiro momento, discutimos o modelo tradicional de aulas expositivas. Em seguida, é sugerida uma metodologia alternativa e, de certa forma, inovadora para que se possa romper com a situação de estagnação da maioria das salas de aula. A estratégia apresentada - o ensino através de projetos - tem o objetivo de colocar 0 professor como coordenador do processo de aprendizagem e investe no protagonismo dos alunos na construção do seu conhecimento.

\section{A AULA EXPOSITIVA TRADICIONAL}

Na maioria das vezes em que uma metodologia diferente da tradicional aula expositiva - muitas vezes também chamada de aula magna - é abordada, surgem dizeres, conceitos e elementos que repreendem a clássica e habitual técnica de ensino. Quase que na totalidade, os julgamentos feitos à aula expositiva servem para enaltecer as características das propostas ditas inovadoras (CUNHA, 2008). Entretanto, apesar da enxurrada de críticas, o modelo expositivo tradicional continua sendo avassaladoramente dominante como metodologia de ensino na educação básica. Esse estilo já está massificado em função do uso de tal prática ao longo da história da educação. Em nosso país, Cândido (2012) afirma que é possível perceber que a aula expositiva "se consolidou como prática pedagógica pelas mãos dos jesuítas, se transformando na estratégia mais utilizada nas escolas até os dias de hoje" (p. 62-63).

Em função do contínuo uso da técnica expositiva ao longo da nossa trajetória histórica, é possível perceber e concluir que toda a estrutura educacional que construímos e montamos está relacionada com esta metodologia. Ou seja, o sistema favorece esse tipo de processo. Se analisarmos com cuidado, desde a edificação e disposição das nossas salas de aula, passando pelos mobiliários e recursos básicos das mesmas, até a formação de nossos professores, inevitavelmente, quase tudo aponta para o uso e para a continuidade desta estratégia de ensino. É por isso que Lima (2008) afirma 
que "a aula expositiva é, sem dúvida, o procedimento didático mais amplamente utilizado pelos professores" (p. 99).

A metodologia de aula expositiva confunde-se com aquilo que chamamos de escola tradicional. Suas origens estão arraigadas às primeiras concepções de escola enquanto instituição, surgida em nosso país no século XIX com o advento da escolarização em massa. Esses educandários foram os rudimentos da organização em forma de classes que contavam com "um professor que expunha as lições que os alunos seguiam atentamente e aplicava os exercícios que os alunos deveriam realizar disciplinadamente" (SAVIANI, 1999, p. 18). Nesse início da escolarização, segundo Leão (1999), a abordagem tradicional apoiava-se na ideia de que a inteligência estava intrinsicamente ligada à capacidade de armazenar informações e o conhecimento possuía um caráter cumulativo. Assim, nesta situação, "o papel do indivíduo no processo de aprendizagem é basicamente de passividade" (LEÃO, 1999, p. 190).

A aula expositiva tem como característica própria, como naturalidade intrínseca, a forte dependência do professor. É ele o responsável pela condução das ações que têm por objetivo principal levar os alunos a um determinado conhecimento ou aprendizagem. Passa pelo professor todo o planejamento e ação das rotinas pedagógicas que visam manter a classe organizada e atenta. É do professor a responsabilidade de trabalhar no nível cognitivo condizente à intelectualidade dos aprendizes. É dele que se espera a habilidade quase que mágica de atuar no individual e, ao mesmo tempo, a favor da coletividade. É muitas vezes da sua experiência que partem os recortes de conteúdos e a ênfase de conceitos que irão compor o programa de curso ou de disciplina.

Além da vinculação à figura do professor, a aula expositiva pode ser preferida com alguns benefícios em relação a outros métodos em dadas circunstâncias. Com a vantagem de ser uma tarefa de baixo custo, ela se adapta muito bem a situações em que temos um número grande de alunos, inviabilizando tarefas em laboratórios ou grupos de discussão, sendo também conveniente em locais em que existam poucos recursos didáticos. Igualmente ela é preferida quando há a necessidade de sintetizar um assunto que é muito amplo, em situações em que é fixado um período limitado para a explanação, como por exemplo, na escola básica em que um conjunto de conteúdos deve ser trabalhado em um determinado período específico. Além disso, ela é fácil de planejar, de adequar-se ao tempo disponível, possibilita gerenciar de modo eficaz o trio introdução, desenvolvimento e conclusão e uma série de outros proveitos.

É importante destacar que não há nada essencialmente errado com a aula expositiva que mereça a recriminação e a crítica que ela normalmente recebe por parte daqueles que defendem práticas mais inovadoras. Talvez algumas de suas características não agradem aos defensores de metodologias mais dinâmicas, o que leva ao desgaste da imagem da aula expositiva clássica. O problema ocorre quando a aula expositiva é a única metodologia utilizada, pois ela torna-se rotineira e termina sofrendo uma degradação natural. Se a aula expositiva não for bem conduzida, ela certamente produzirá maus resultados o que, também, lançará corrosões em sua imagem.

Entretanto, a maior dificuldade do processo expositivo encontra-se justamente quando ele não cumpre o seu efetivo papel, dando margem para que se corra o risco da não aprendizagem. É nessa direção que as críticas deveriam apontar e não somente no método em si, pois, afinal, na maioria das escolas a aula expositiva está fortemente em vigor, e é indiscutivelmente a metodologia didática mais utilizada. Duas formas desta não aprendizagem acontecer encontram-se justamente na ocorrência da 
distância do diálogo educativo entre o professor e os alunos e, principalmente, quando existir passividade dos aprendizes frente ao objeto de conhecimento. Oliveira (2006) sintetiza muito bem o quadro em que a aula expositiva não tem funcionalidade:

[...] o professor passa para o aluno, através da exposição verbal da matéria, de exercícios de memorização e fixação de conteúdos, de leituras em livros didáticos, os conhecimentos adquiridos ao longo dos anos pelas diferentes culturas. $\mathrm{O}$ aluno recebe tudo pronto, não é incentivado a problematizar e nem é solicitado a questionar ou fazer relação do que aprende com o que já conhece. Por isso, é frequentemente caracterizado como passivo (p. 2).

A representação relatada na citação anterior aponta o que de pior pode ocorrer numa aula expositiva. No momento em que o professor impõe demasiadamente as suas condições, ele tira do aluno a capacidade de interpretação, analogia e ampliação do conhecimento. Igualmente, quando o aprendiz se coloca apático e alheio ao conhecimento, indiferente à apresentação do conteúdo, quando ele apenas fica na espera das próximas cenas, sem inquirir ou contextualizar aquilo que recebe, a aula fica sem sentido, fica hipotética e desvinculada do mundo real. Cabe ao educador ter tato e sensibilidade a fim de não permitir que esta situação venha a ocorrer.

Assim, quando nada é feito para evitar ou contornar esse quadro, a aula expositiva torna-se desonesta e perversa. Esta proposta com estes aspectos caracteriza-se fortemente por sua ação modeladora e conformadora. O professor, deste jeito, acaba subjetivando e impondo suas perspectivas, seus pontos de vistas e ideologias, a partir do pressuposto de que tal metodologia possibilita o ganho de tempo, precisão, rapidez e facilidade (OLIVEIRA, 2006). Como consequência da aplicação da aula expositiva nos moldes inconvenientes, tem-se agravado cada vez mais aquele que certamente é o maior dos problemas da educação brasileira: a não aprendizagem por parte do aluno. Pelo fato desta metodologia permitir tal postura se estendendo por sucessivos anos, temos deformado os alunos e os próprios professores. Temos visto o professor muito mais preocupado em tentar vencer o conteúdo e manter a ordem e a disciplina na sala. Enquanto isso, percebemos que os alunos cada vez mais se empenham em seguir estratégias que os façam passar o tempo da aula afastados da monotonia da mesma. O resultado é desastroso, pois desta forma o aluno não aprende.

Nesta situação, o aprendiz dificilmente conseguirá envolver-se na construção do seu conhecimento, o que é a premissa básica do ato de aprender segundo as perspectivas construtivistas. No seguimento destas ações, ou seja, quando a aula expositiva não funciona, os alunos acabam optando por caminhos alternativos para enfrentar as avaliações e serem aprovados. O conhecimento não importa. O que vale é decorar algumas coisas, fazer alguns trabalhos, se possível, coletivamente e passar de ano. Tudo isso frustra demasiadamente o professor que não se sente estimulado ao perceber a ineficácia de seu esforço. O que lhe resta são fadiga e desilusão. Do outro lado, os alunos se desvirtuam, perdem o espirito da auto responsabilidade pelo seu aprendizado, desfiguram-se, caminham sem direção e direcionamento. De quebra, acabam carregando o trauma e todo o tipo de más impressões destas experiências por toda a vida, ocasionando, inclusive, a desistência de alguns do processo educativo. Aqueles que persistem ficam deformados educacionalmente, pois, pelo fato de receberem sempre tudo pronto e resumido, de não terem a responsabilidade de buscar 0 conhecimento, tornam-se acomodados, sem iniciativas e, por isso, resistentes a novas aprendizagens e novos desafios. 
Na contramão da escola tradicional, surge a perspectiva da inovação pedagógica (FINO, 2007; CUNHA, 2008). Costumeiramente associada à utilização da tecnologia como auxílio nos processos de ensino e aprendizagem, vários autores têm defendido a inovação enquanto uma visão relativa à mudança nos processos educativos. São tentativas de oferecer alternativas às metodologias clássicas e habituais. Cunha (2008), por exemplo, defende uma ruptura com os paradigmas tradicionais, inspirados numa visão positivista. Para este autor, aderir: a uma "ruptura paradigmática significa o reconhecimento de outras formas de produção de saberes, incorporando a dimensão sócio-histórica do conhecimento e sua dimensão axiológica que une sujeito e objeto" (CUNHA, 2008, p. 24). É nesse sentido que trazemos à tona uma metodologia didática que está embasada no ensino por meio e pelo uso de projetos.

\section{ENSINO ATRAVÉS DE PROJETOS}

Para implementar algo diferente em relação às práticas pedagógicas, o Ensino Através de Projetos, vem a ser uma alternativa didática eficiente para que o professor mude a estrutura comprometedora que a aula expositiva pode gerar. $O$ ensino através de projetos também vem a ser útil na medida em que, muitas vezes, os livros didáticos, tão comuns na rotina escolar, não estimulam aos aprendizes à utilização de pesquisa e de procedimentos de construção do conhecimento (PEREIRA et al., 2011). Da mesma forma, o ensino através de projeto pode resultar numa fácil forma de contextualização dos conteúdos e no desenvolvimento de competências e habilidades (SILVA et al., 2008), atuando desde o nível lúdico até o real.

Como já comentado anteriormente, o aprendiz deve ser aquele sujeito envolvido e comprometido com a construção do seu próprio saber. Com apoio na experimentação prática e na vivência intelectual, sensorial e emocional do conhecimento (OLIVEIRA, 2006), a metodologia do ensino através de projetos atua fortemente na promoção de situações onde o conceito central está relacionado ao aprender fazendo. Proporcionar aos alunos condições teóricas e práticas para que eles utilizem, transformem e compreendam o mundo da forma mais responsável possível, também é papel de tal metodologia.

O ensino através de projetos não é algo novo. Basta passar os olhos nos anais dos encontros sobre ensino e aprendizagem ou uma rápida busca nos bancos de dados eletrônicos e nos sítios de procura da web para percebermos a intensa produção sobre o assunto (KRASILCHICK, 1996; HERNÁNDEZ; VENTURA, 1998; OLIVEIRA, 2006; SILVA et al, 2008; PEREIRA et al., 2011; BARBOSA; MOURA, 2011). As definições em torno da temática são as mais diversas, mas não fogem de acepções que envolvam propostas pedagógicas disciplinares ou interdisciplinares, com a orientação de um ou mais professores. Sua execução ocorre, geralmente, no contexto escolar e é composta de atividades a serem desempenhadas por um ou por um grupo de alunos. O desenvolvimento do projeto prevê uma interação entre professores e aprendizes de forma dinâmica e dialógica servindo para a resolução de um problema e/ou a construção de um objeto, equipamento, relatório, protótipo, enfim, um produto final concreto. Em termos de objetivos, o ensino através de projetos está alicerçado na criação de uma situação de aprendizagem que ofereça o desenvolvimento de competências e habilidades, na discussão de valores e na análise e interpretação de situações cotidianas, suscitando reflexões, preparo para a vida e a construção da aprendizagem. 
Em sua natureza, a pedagogia de projetos sugere romper com as formas metodológicas tradicionais de organização curricular. Sua concepção básica inverte a lógica hegemônica escolar, derruba a organização característica do currículo e da maior parte dos livros didáticos e abusa da criatividade e do planejamento dos professores. O ensino através de projetos permite a abertura de uma real perspectiva de diálogo entre o professor e os alunos, permitindo que estes construam sua própria aprendizagem enquanto sujeitos ativos, autônomos, criativos e responsáveis. Prado (2005) também compartilha essa ideia: "na pedagogia de projetos, o aluno aprende no processo de produzir, levantar dúvidas, pesquisar e criar relações que incentivam novas buscas, descobertas, compreensões e reconstruções de conhecimento" (p. 13).

Evidentemente, não se está aqui querendo exterminar com o método tradicional de aulas expositivas, pois, afinal, como já comentado anteriormente, o método por si só não é o problema, mas, a maneira perversa do como ele pode ser conduzido. Quem sabe, uma situação próxima do ideal seria aquela em que diversas metodologias pudessem ser intercaladas em benefício do ensino e da aprendizagem, que configurassem situações para que o aprendiz construísse seu próprio conhecimento. O que se está querendo propor é justamente o extermínio da passividade do aluno e a aproximação de docentes e discentes no processo educativo.

Contudo, há de se dizer que, se no método tradicional a aula tem uma aguda dependência do professor, isso não se fará diferente no ensino através de projetos. Nesse caso, ele também deverá assumir ações e responsabilidades em prol da aprendizagem do aluno, mas, em outra esfera, em outro modo de atuação, pois ainda nas palavras de Prado (2005):

[...] o papel do professor deixa de ser aquele que ensina por meio da transmissão de informações - que tem como centro do processo a atuação do professor - para criar situações de aprendizagem cujo foco incida sobre as relações que se estabelecem nesse processo, cabendo ao professor realizar as mediações necessárias para que o aluno possa encontrar sentido naquilo que está aprendendo a partir das relações criadas nessas situações (p. 13).

Certamente aí está um dos grandes desafios dessa metodologia, pois quando o professor estabelece o planejamento de uma aula expositiva, ele fica inteiramente com o controle de toda a situação. Sob o seu comando estão todos os passos que deverão ser dados para a condução da aula. É ele quem irá estabelecer a sequência, a progressão, as etapas e a profundidade do conteúdo em questão. No entanto, no ensino através de projetos são os temas a serem investigados por meio de planos e atos que colocam o currículo em ação. A produção do conhecimento é imprevisível e a idealização inicial deve ser repensada e refeita a todo instante. Os papéis são diferentes, pois o professor assume a tarefa de coordenador e o aluno o de sujeito ativo em seu processo de aprendizagem. A relação entre eles é horizontal, ambos tomam decisões após a argumentação e defesa de suas opiniões. Convivese o tempo todo com as surpresas, com o inesperado, com situações em que nem se havia imaginado. O que para alguns pode ser visto como um desafio a ser seguido, como uma nova ideia ou um novo rumo, para outros, essa imponderabilidade pode ser recebida como fracasso, como caos, como uma circunstância de estresse ou de perda de controle.

Indo nessa mesma lógica, a metodologia de ensino através de projetos pode não ser bem sucedida se não tiver a participação dos colegas, a aceitação irrestrita da direção da escola e a anuência dos pais ou responsáveis. Como essa metodologia é dinâmica e dialógica, a sala de aula perde as 
características da aula tradicional, o que pode ser visto como bagunça por quem não esteja envolvido no processo. Da mesma forma, o ambiente da sala de aula nem sempre será o local de estudos. Nesse tipo de didática, é comum vermos os alunos espalhados pela escola, frequentando muito mais os espaços disponíveis, tais como o pátio, os laboratórios, as quadras esportivas, a cozinha, a biblioteca, etc. Os desavisados podem vir a pensar que o professor não está dando aula! Outro aspecto que é difícil de contornar é a situação de avaliação. A observação da execução de um projeto pode ser também uma ocasião de avaliação. O produto final apresentado pelos alunos, o modo como se organizam, os relatórios e a mudança em seus conceitos e discursos certamente dão indícios de suas aprendizagens. Se o professor usar esses aspectos para a avaliação dos alunos, isso precisa ser entendido e aceito pela comunidade escolar que não deve criticar o professor por não ter feito uma prova formal.

Neste sentido, a própria metodologia cria um caminho natural para a avaliação mediadora (HOFFMANN, 2003), a qual se caracteriza por uma maior atenção ao aluno, de forma a conhecê-lo melhor. Tal situação passa pela prática de ouvir seus argumentos, fazer novas e desafiadoras questões e buscar alternativas para uma ação educativa voltada para a sua autonomia moral e intelectual. $\mathrm{O}$ ensino através de projetos estaria assim também centrado e engajado numa:

[...] perspectiva da ação avaliativa como uma das mediações pela qual se encorajaria a reorganização do saber. Ação, movimento, provocação, na tentativa de reciprocidade intelectual entre os elementos da ação educativa. Professor e aluno buscando coordenar seus pontos de vista, trocando ideias, reorganizando-as (HOFFMANN, 2003, p. 67).

Não existe uma receita pronta para o planejamento, execução e avaliação de um projeto para ser usado enquanto metodologia didática. O tipo de assunto, a disponibilidade e o interesse do professor e da escola, os recursos materiais, físicos e financeiros, a possibilidade de ser executável, o tempo disponível, a aceitação e o comprometimento dos alunos, etc. são alguns dos pontos a serem levados em conta quando o assunto é o ensino através de projetos. Um dos trabalhos bastante esclarecedores sobre o tema é o texto de Hernández e Ventura (1998). Nele, os autores discutem os principais atributos que envolvem tal processo e comentam sobre os aspectos mais relevantes na organização e condução desta metodologia. A partir daqui, destaco três características que um projeto deve conter a fim de que seja executado com vistas à obtenção dos melhores resultados. Em primeiro lugar, o ponto de partida para o ensino através de projetos é a escolha do tema. Respeitando-se o nível e a etapa da escolaridade, Hernández e Ventura (1998) sugerem que o tema seja escolhido a partir do próprio currículo, ou de uma experiência comum da turma, ou de um fato da atualidade, ou de um assunto proposto pelo professor, etc., sempre levando em conta a relevância e a importância da escolha para o crescimento de todos. Também é muito importante que os alunos tenham experiências anteriores com relação ao trabalho com projetos. Caso os alunos nunca tenham realizado projetos de ensino, o ideal é que eles tomem conhecimento da metodologia seja pelo exemplo de outras turmas, de classes de outra instituição ou por outro método (vídeos, relatos, etc.) que venha a lhes favorecer o entendimento da experiência que estão prestes a viver.

A segunda característica para o bom andamento da metodologia é que o professor esteja ciente de suas atividades durante o projeto. Hernández e Ventura (1998) apontam alguns itens que devem ser observados pelos coordenadores da atividade, tais como: ter clareza e especificar como serão os processos de condução que permitirão que o projeto atinja objetivos para além de simples atributos 
informativos ou instrumentais imediatos; prever os conteúdos, as atividades e ter noção das fontes de informação que contribuirão para o desenvolvimento do projeto; atualizar-se em relação ao tema ou problema proposto a fim de que, à medida que o processo avance, os alunos possam construir seus conhecimentos a partir das novidades e informações adquiridas ao longo do andamento do projeto; criar e manter um clima de interesse e envolvimento do grupo a fim de que todos possam aprender individual e coletivamente; ter ideia dos recursos necessários ao desenvolvimento do trabalho; entender que neste tipo de tarefa, a avaliação também pode ter características diferentes daquela que comumente chamamos de tradicional; fazer recapitulações sempre que necessário a fim de que os alunos não venham a perder a visão global do projeto.

Por fim, outra peculiaridade desta metodologia está relacionada ao papel e compromissos dos alunos. Nesta terceira característica, os autores apontam que os alunos têm as seguintes funções: inicialmente produzir uma espécie de índice ou cronograma pessoal de trabalho a fim de que possam planejar o tempo que terão que investir, os recursos, os procedimentos e as atividades que terão que realizar. Além disso, este cronograma é útil para que se tenha a visão geral do trabalho, para que todos tenham noção de suas tarefas e das dos outros e como instrumento de compromisso e de avaliação; ter um roteiro com o planejamento geral do grupo; conhecer ou familiarizar-se com as fontes das quais irão extrair as informações e os conhecimentos necessários ao andamento do projeto (bibliotecas, computadores, museus, parques, universidades, etc.); realizar individual ou coletivamente o tratamento das informações que foram coletadas a partir das fontes consultadas; cumprir com as atividades as quais ficaram comprometidos no cronograma e no roteiro de trabalho; apresentar as conclusões conforme o planejado (dossiê, vídeo, apresentação oral, produto final, etc.); entender que assim como qualquer outra atividade de ensino e aprendizagem, a avaliação é parte integrante do processo.

Enfim, não há como não admitir que o ensino através de projetos possa constituir-se num fator motivacional na atividade de professores e alunos. Tal técnica tem muitos quesitos com características que certamente podem alavancar o processo de aprendizagem onde o aluno coloca-se como construtor do seu conhecimento. Infelizmente a maioria dos professores não foi preparado para tal metodologia. Seria preciso investir nas licenciaturas para que os futuros professores incorporassem tal prática. A formação do professor receptivo a novas metodologias poderia dar condições de a escola assumir um papel diferente da realidade atual. Ao mesmo tempo, os cursos de formação continuada seriam uma alternativa importante para divulgação, aplicação e troca de experiências visando à conscientização da aplicação do ensino através de projetos por aqueles docentes que já se encontram no mercado de trabalho, longe dos bancos universitários.

\section{CONCLUSÃO}

Ao se estabelecer uma comparação entre as duas metodologias didáticas aqui apresentadas, não há como negar a gritante diferença entre elas. No entanto, cada uma pode ter o seu espaço no contexto escolar. A partir da crença em que os alunos são os responsáveis pela construção dos seus próprios saberes, o professor pode planejar sua prática intercalando essas duas propostas e incluindo outras em seu fazer pedagógico. Evidentemente, o ensino através de projetos é muito mais propositivo aos preceitos do ensino cognitivista uma vez que, segundo Oliveira (2006) ele: 
[...] permite o trabalho com grupos cooperativos, cria condições para que os alunos experimentem suas descobertas, desenvolvam a confiança na própria capacidade de aprender e tomar decisões, fazer escolhas apropriadas na vida. Possibilita também praticar o ouvir e refletir sobre fatos; defender a si mesmo e suas ideias de forma apropriada; tomar providências para concretizar objetivos; dizer a verdade, honrar compromissos e servir de exemplo (p. 18).

Cabe ao professor compreender a qualidade do andamento de suas aulas e, diante da percepção da não aprendizagem, utilizar abordagens diferentes para que possa promover o entendimento e crescimento cognitivo de seus aprendizes. Ao utilizar técnicas mais dinâmicas, o professor também estará promovendo mudanças não só na sua sala de aula, mas na escola como um todo. Envolver a comunidade escolar no entendimento e na ação de um ensino mais ativo e significativo seria um grande passo para uma mudança oportuna na qualidade da educação e na imagem da instituição escolar.

Podemos ainda apontar que o trabalho através de projetos traz para a realidade escolar espaços de interação entre professores, alunos e áreas de conhecimento, podendo ser enxergado como um avanço em direção à interdisciplinaridade proposta nos documentos oficiais. Apesar de não caracterizada pelo que os teóricos apontam como principal paradigma da interdisciplinaridade, que é a eliminação das barreiras disciplinares, um olhar mais atento mostra que o trabalho com projetos permite a integração de conteúdos, seja através de temas comuns, seja através de práticas comuns.

Conforme apontamos ainda, a grande questão em aberto está na formação inicial dos professores, quer para trabalhar com projetos, quer para trabalhar em conjunto. Finalizamos sinalizando que uma revisão nesta formação se torna necessária, considerando a emergência da inovação pedagógica para o ensino básico.

\section{REFERÊNCIAS}

ALMEIDA, Maria Elizabeth Bianconcini de; MORAN, José Manuel. (Org.). Integração das tecnologias na educação. Brasília: Ministério da Educação/SEED/TV Escola/Salto para o Futuro, 2005. cap. 1, artigo 1.1, p. 12-17. Disponível em: <http://www.tvbrasil.org.br/saltoparaofuturo/livros.asp>. Último acesso em: 12 ago. 2016.

BARBOSA, Eduardo Fernandes; MOURA, Dácio Guimarães. Trabalhando com projetos - Planejamento e Gestão de Projetos Educacionais. São Paulo: Vozes, 2011.

CÂNDIDO, Willian. A nova e velha mesmice da aula expositiva. In: Simpósio de Pedagogia, 12, 2012, Goiânia. Anais... Goiânia, 2012. Disponível em: <http://educacao.catalao.ufg.br/publicacoespedagogia/index.php/simposiopedago/article/download/ 126/100>. Último acesso em: 05 ago. 2016.

CUNHA, Maria Isabel da. Inovações pedagógicas: o desafio da reconfiguração de saberes na docência universitária. Cadernos Pedagogia Universitária USP, vol 6. São Paulo: Pró-Reitoria de Graduação da Universidade de São Paulo. 2008. 40 pp.

FINO, Carlos Nogueira. Inovação Pedagógica: Significado e Campo (de investigação). In: MENDONÇA, Alice; BENTO, Antônio V. (Org). Educação em tempo de mudança. Funchal: Grafimadeira, 2008. p. 277-287. 
HERNÁNDEZ, Fernando; VENTURA, Montserrat. A organização do currículo por projetos de trabalho: o conhecimento é um caleidoscópio. Porto Alegre: Artes Médicas, 1998.

HOFFMANN, Jussara. Avaliação Mediadora: uma prática em construção da pré-escola à universidade. 14. ed. Porto Alegre: Mediação, 2003.

KRASILCHIK, Myriam. Prática de Ensino de Biologia. 3 ed. São Paulo: Ed Harbra, 1996.

LEÃO, Denise Maria Maciel. Paradigmas contemporâneos de educação: escola tradicional e escola construtivista. Cadernos de Pesquisa, n. 107, p. 187-206, jul. 1999. Disponível em: <http://www.scielo.br/pdf/cp/n107/n107a08.pdf>. Último acesso em: 08 ago. 2016.

LIMA, Valderez Marina do Rosário. Aula expositiva in: FREITAS, Ana Lúcia Souza de et al. (org). A gestão da aula universitária na PUCRS. Porto Alegre: EDIPUCRS, 2008. Disponível em: <http://www.pucrs.br/edipucrs/agestaodaaula.pdf>. Último acesso em: 05 ago. 2016.

OLIVEIRA, Cacilda Lages. Significado e contribuições da afetividade, no contexto da Metodologia de Projetos, na Educação Básica. Dissertação de Mestrado - CEFET-MG, Belo Horizonte, 2006.

Disponível

em:

<http://www.tecnologiadeprojetos.com.br/banco_objetos/\%7B28A0E37E-294A-4107-906C-

914B445E1A40\%7D_pedagogia-metodologia.pdf>. Último acesso em: 05 jun. 2016.

PEREIRA, Marsilvio Gonçalves; ROCHA, Gewerlys Stallony Diego Costa da; BARBOSA, Alessandro Tomaz. Projetos de ensino: possibilidades para ensinar e aprender em ciências e biologia. In: V Colóquio Internacional "Educação e Contemporaneidade". São Cristóvão - SE, 2011. Anais... São Cristóvão, 2011. Disponível em: <http://www.educonufs.com.br/vcoloquio/>. Último acesso em: 01 jun. 2014.

PRADO, Maria Elisabette Brisola Brito: fundamentos e implicações. In: SAVIANI, Demerval. Escola e democracia: teorias da educação, curvatura da vara, onze teses sobre educação e política. 32. ed. Coleção Polêmicas de Nosso Tempo, v. 5. São Paulo: Autores Associados, 1999. Disponível em: <http://xa.yimg.com/kq/groups/23100729/29821536/name/dermeval>. Último acesso em 08 ago. 2016.

SILVA, Petronildo Bezerra da; BEZERRA, Vilma Sobral; GREGO, Ailton; SOUZA, Lúcia Helena Aguiar de. A Pedagogia de Projetos no Ensino de Química - O Caminho das Águas na Região Metropolitana do Recife: dos Mananciais ao Reaproveitamento dos Esgotos. Química Nova Na Escola, n. 29, ago. 2008. Disponível em <http://qnesc.sbq.org.br/online/qnesc29/04-RSA-0307.pdf>. Último acesso em: 10 jun. 2016. 